\title{
Artrite encefalite caprina: avaliação dos aspectos produtivos e reprodutivos de animais infectados e não infectados
}

Elizabeth BOHLAND'; José Luiz D'ANGELINO²

\section{Correspondência para:} ELIZABETH BOHLAND

Faculdade de Medicina Veterinária

Universidade Santo Amaro

Rua Prof. Enéas de Siqueira Neto, 340

Jardim das Imbuias

04829-300 - São Paulo - SP

ebohland@uol.com.br

Received:31/07/2003

Accepted:22/06/2004

\author{
1- Faculdade de Medicina Veterinária da Universidade de Santo Amaro, \\ São Paulo - SP \\ 2- Departamento de Clínica Médica da Faculdade de Medicina Veterinária \\ e Zootecnia da USP, São Paulo - SP
}

\section{Resumo}

O objetivo foi avaliar os aspectos produtivos e reprodutivos, de caprinos leiteiros, reagentes e não reagentes à prova de imunodifusão em ágar gel (IDAG), utilizando os antígenos gp135 e p28 do vírus da Artrite Encefalite Caprina (CAE). Os animais pertenciam a uma propriedade localizada no interior de São Paulo e foram acompanhados por um período de 24 meses, tendo sido realizados 3 testes sorológicos, com intervalos de 12 meses. A freqüência de ocorrência da CAE, nos três momentos foi respectivamente, $60,1 \%$, $74,1 \%$, e $70,5 \%$ (média de $68,3 \%$ - 566/829). O percentual de animais reagentes aumentou significativamente com a idade. A duração média da lactação (dias) foi menor para reagentes e significativa nas faixas etárias 24 a 36 meses e 36 a 48 meses. A produção leiteira (kg./dia) foi menor para reagentes e significativa nas faixas etárias: 12 a 24 meses maior ou igual a 48 meses. A produção total por lactação foi $21,5 \%$ menor para as cabras soropositivas. A CAE não influenciou os aspectos reprodutivos neste estudo no que se refere à idade ao primeiro parto, ao intervalo interpartos. No entanto, a média de idade ao parto entre os animais reagentes foi maior e estatisticamente significante e o peso das crias nascidas de mães reagentes com idade maior ou igual a 48 meses foi menor do que os animais nascidos de cabras não reagentes.

\section{Introdução}

A Artrite Encefalite Caprina (CAE) é uma doença infecciosa, multissistêmica, causada por um RNA vírus da Família Retroviridae, gênero lentivírus que infecta células do sistema mononuclear fagocitário, resultando na produção de anticorpos contra as proteínas do núcleo e do envelope viral ${ }^{1}$. Descrita primeiramente por Cork et a. ${ }^{2}$, em cabritos natural e experimentalmente infectados. É caracterizada por sua natureza crônica de aspecto insidioso, tendo como principal manifestação clínica a artrite, que acomete preferencialmente animais adultos ${ }^{3}$ podendo também ser encontradas alterações na glândula mamária ${ }^{4}$, sistema nervoso ${ }^{2}$, pulmões ${ }^{5}$ e útero ${ }^{6}$.

A CAE foi descrita em vários países do mundo ${ }^{7}$. No Brasil, o primeiro relato da doença foi feito por Moojen et al. ${ }^{8}$. Posteriormente, surgiram relatos da ocorrência da doença em vários estados deste país ${ }^{9,10,11,12,13,14}$, mostrando que a mesma se encontra disseminada em nosso meio.

Diante da inexistência de tratamento da CAE, as medidas de controle são fundamentais para prevenir o avanço da doença nos rebanhos caprinos. Os programas de controle estão baseados na prevenção das várias formas de transmissão da doença, ou seja, evitando a ingestão de colostro e leite contaminado ${ }^{15,16,17}$, a transmissão por contato direto com secreções como $^{17}$ : urogenitais ${ }^{6,16}$

\author{
Palavras-chave: \\ Produção leiteira. \\ Reprodução. \\ Caprinos
}


e do trato respiratório ${ }^{18}$, o uso de tatuadores, instrumentos cirúrgicos e outros fômites contaminados com sangue ${ }^{19,20}$ e do acompanhamento da eficácia destas medidas através de testes sorológicos periódicos ${ }^{20}$.

Alguns pesquisadores têm demonstrado preocupação em estudar o impacto econômico causado pela CAE na produção leiteira e na reprodução ${ }^{21,22,23,24}$. Desta forma o vírus da CAE tem sido associado à menor produção de leite ${ }^{21,23}$, ao aparecimento de doenças no úbere $^{4,16}$, aumento de células somáticas ${ }^{4,25}$, a ocorrência de mortalidade no período neonatal $^{22}$, falhas reprodutivas ${ }^{21,24}$ e ao maior descarte de animais doentes ${ }^{26}$.

Considerando a ausência de pesquisas em nosso meio, idealizou-se o presente estudo. Visando estudar o impacto econômico da CAE num rebanho caprino, este trabalho tem como objetivo avaliar e analisar a influência da doença sobre os aspectos produtivos e reprodutivos dentro de uma propriedade, considerando os seguintes parâmetros: duração da lactação, média diária de produção de leite, produção total por lactação, idade ao primeiro parto, idade ao parto, intervalo interpartos e peso das crias ao nascer.

\section{Materiais e Métodos}

Os animais utilizados neste estudo pertenciam a uma propriedade leiteira, localizada no interior de São Paulo. A criação de caprinos se iniciou em 1986, com a importação de animais da França. Os animais são criados em regime intensivo, sendo vacinados anualmente contra Febre Aftosa e vermifugados a cada quatro meses. $\mathrm{Na}$ exploração leiteira é utilizada a ordenha mecânica e manual. Esta última, para esgotamento e pesagem do leite que é realizada mensalmente. $\mathrm{Na}$ reprodução é utilizada a monta natural, com auxílio de rufião. As cabritas são cobertas a partir de 7 meses de idade ou quando atingem um peso vivo de 35 quilogramas.

\section{Colheita de Material}

As amostras de sangue, aproximadamente $10 \mathrm{ml}$ de cada animal, foram colhidas por venopunção da jugular externa em tubo à vacuo sem anticoagulante ${ }^{4}$, sendo mantidas em temperatura ambiente até a coagulação e transportadas até o laboratório. No Laboratório de Imunodiagnóstico do Departamento de Clínica Médica da Faculdade de Medicina Veterinária e Zootecnia da USP, o sangue foi centrifugado a 5000 f.c.m., durante quinze minutos, para a obtenção do soro que foi armazenado em frascos estéreis e congelado a $-20{ }^{\circ} \mathrm{C}$, até a realização da prova de imunodifusão em ágar gel (IDAG).

\section{Prova sorológica}

A pesquisa de anticorpos séricos para o vírus da CAE, foi realizada através da prova de IDAG para a CAE, segundo a técnica preconizada por Cutlip, Jackson e Laird ${ }^{28}$, utilizando os antígenos glicoprotéico (gp135) e protéico (p28) extraídos respectivamente, do envelope e do núcleo do vírus (produzidos pelo Veterinary Diagnostic Technology, Inc., Colorado, Estados Unidos).

\section{Metodologia}

Os animais avaliados neste estudo foram acompanhados por um período de 24 meses, tendo sido realizados 3 testes sorológicos, com intervalos de 12 meses entre cada um. Nestas ocasiões o rebanho total apresentava, respectivamente, 301, 352 e 176 animais, totalizando 829 animais. O estudo da distribuição de reagentes e não reagentes à prova de IDAG para CAE segundo a idade, foi feito através da estratificação dos animais em faixas etárias: 0 a 6 meses, 7 a 12 meses, 12 a 24 meses 24 a 36 meses, 36 a 48 meses e maiores de 48 meses, com dados referentes a 759 animais, devido à ausência de informações detalhadas nas fichas compiladas.

Os dados referentes às características produtivas e aos aspectos reprodutivos foram obtidos de fichas individuais de produção ${ }^{26}$, fornecidas pelo encarregado do capril. Estas informações foram relacionadas em um banco de dados, do programa EPI INFO 
$6^{29}$, para serem posteriormente analisadas.

Para a avaliação dos aspectos produtivos e reprodutivos, os animais foram observados por um período de 24 meses, sendo agrupados em reagentes e não reagentes para a CAE, a partir dos resultados obtidos no primeiro teste diagnóstico. Foi admitido que os resultados dos exames, tivessem validade ao longo de cada período, isto é, durante o intervalo entre dois exames consecutivos, quando os animais eram reagrupados de acordo com o resultado do teste e mantidos sob avaliação. Cabe observar que os animais positivos para a CAE, que posteriormente apresentaram resultados negativos (mesmo após o reteste das amostras) foram excluídos do estudo.

A produção leiteira foi verificada, através da avaliação dos registros de 292 fêmeas, com idade igual ou superior a doze meses. Foram utilizados os seguintes parâmetros: duração da lactação (dias), média diária de produção leiteira (kg/dia) e produção total por lactação $(\mathrm{kg})$, analisados segundo a idade.

Para a avaliação dos aspectos reprodutivos, foram avaliados os seguintes parâmetros: idade ao primeiro parto, intervalo interpartos, idade ao parto e peso total das crias ao nascer. A idade ao primeiro parto foi mensurada em meses, sendo utilizadas 113 fêmeas primíparas reagentes e não reagentes, que tiveram parto no período do estudo. As fêmeas que abortaram antes do primeiro parto foram excluídas do estudo. Para a avaliação do intervalo interpartos foram utilizados os dados referentes a 65 fêmeas (com idade igual ou superior a 12 meses) que tiveram dois ou mais partos durante o período e cujo status sorológico se manteve inalterado. A idade ao parto e o peso das crias ao nascer foi mensurada para 303 fêmeas que tiveram partos no período do estudo. $O$ peso das crias nascidas de partos duplos ou triplos obtidos nas fichas de produção referia-se ao peso total do conjunto, não sendo possível determinar o peso de cada uma das crias separadamente.

\section{Análise estatística}

A análise da freqüência de ocorrência da CAE e a estratificação em faixas etárias, foram feitas através do teste de duas proporções $(p=0,05)$, complementado pelo teste do qui-quadrado. As variáveis quantitativas da produção leiteira e dos aspectos reprodutivos foram analisadas mediante o teste de duas médias com aproximação normal $(\mathrm{p}=0,05)$, complementado pelo teste " $\mathrm{t}$ " de student $\mathrm{t}^{30}$.

\section{Resultados}

O percentual de reagentes em cada ano observado foi respectivamente, $60,1 \%$ (181/ $301), 74,1 \%(261 / 352)$ e $70,5 \%(124 / 176)$, apresentando a média de $68,3 \%$ de animais positivos para CAE dentre os 829 estudados. A análise destes resultados mostrou, através do teste de duas proporções, que o percentual de reagentes ao vírus da CAE em 1995 foi menor quando comparado ao número de reagentes em $1996(\mathrm{z}=3,8 ; \mathrm{p}=0,05)$ e em $1997(\mathrm{z}=2,3 ; \mathrm{p}=0,05)$. A distribuição da doença nas diferentes faixas etárias e as diferenças encontradas entre os grupos estão demonstradas na tabela 1 . Os resultados obtidos com a avaliação de 292 fêmeas em lactação, considerando os valores médios obtidos, mostraram que a duração da lactação foi 37 dias menor e a produção total por lactação foi 94,6 litros (21,5\%) menor para os animais soropositivos (Tabela 2). A estratificação dos animais por idade mostrou que as maiores diferenças para a duração da lactação ocorreram para as cabras reagentes com idade entre 24 a 36 meses e maiores de 48 meses. A produção média diária de leite foi $20 \%$. menor para os animais positivos para CAE pertencentes as faixas etárias entre $12 \mathrm{e}$ 24 meses e maiores de 48 meses. A produção total por lactação de cabras reagentes ao vírus da CAE apresentou os piores resultados nas faixas etárias entre 24 a 36 meses e maiores que 48 meses (Tabela 3). Em relação aos aspectos reprodutivos, os resultados desta análise, mostraram diferenças estatisticamente significantes para os valores médios de idade ao parto que revelaram que as cabras reagentes à prova de IDAG para CAE apresentaram 
Tabela 1 - Número e percentual de reagentes e não reagentes à prova de IDAG para CAE, segundo a idade, no período de 19951997. São Paulo, 2003

\begin{tabular}{|c|c|c|c|c|c|}
\hline \multirow[t]{2}{*}{ Idade (meses) } & \multicolumn{2}{|c|}{ Reagentes } & \multicolumn{2}{|c|}{ Não Reagentes } & \multirow{2}{*}{$\begin{array}{c}\text { Total } \\
\text { n }\end{array}$} \\
\hline & $\mathrm{n}$ & $\%$ & $\mathrm{n}$ & $\%$ & \\
\hline $0 \mid-6$ & 4 & $26,7^{a}$ & 11 & 73,3 & 15 \\
\hline $6-12$ & 139 & $67,2^{b}$ & 68 & 32,9 & 207 \\
\hline $12 \mid-24$ & 134 & $68,0^{b}$ & 63 & 32,0 & 197 \\
\hline $24 \mid-36$ & 82 & $70,1^{b}$ & 35 & 29,9 & 117 \\
\hline $36 \mid-48$ & 62 & $67,4^{b}$ & 30 & 32,6 & 92 \\
\hline$=48$ & 107 & $81,7^{\mathrm{c}}$ & 24 & 18,3 & 131 \\
\hline TOTAL & 528 & 69,6 & 231 & 30,4 & 759 \\
\hline
\end{tabular}

letras não coincidentes denotam diferença estatísticamente significante $(p=0,05)$

Tabela 2 - Valores médios e desvios padrão (d.p.) encontrados para as variáveis quantitativas de produção e reprodução de cabras reagentes e não reagentes ao teste de IDAG para CAE e os valores do teste estatístico, no período de 1995-1997. São Paulo, 2003

\begin{tabular}{|c|c|c|c|c|c|}
\hline & \multicolumn{2}{|c|}{ Reagentes } & \multicolumn{2}{|c|}{ Não Reagentes } & \\
\hline & $\mathrm{n}$ & Média \pm d.p. & $\mathrm{n}$ & Média \pm d.p. & \\
\hline Duração da lactação (dias) & 198 & $217,0 \pm 91,6$ & 94 & $254,1 \pm 103,4$ & $3,10 \mathrm{~S}$. \\
\hline Média diária (kg/dia) & 198 & $1,6 \pm 0,7$ & 94 & $1,8 \pm 0,7$ & 1,73 N.S. \\
\hline Produção total /lactação (kg) & 198 & $346,3 \pm 183,4$ & 94 & $440,9 \pm 228,1$ & $3,52 \mathrm{~S}$. \\
\hline Idade ao primeiro parto (meses) & 70 & $19,3 \pm 5,1$ & 43 & $19,0 \pm 5,6$ & 0,30 N.S. \\
\hline Idade ao parto (meses) & 211 & $37,8 \pm 18,9$ & 92 & $31,2 \pm 15,4$ & $3,19 \mathrm{~S}$ \\
\hline Intervalo interpartos (dias) & 49 & $335,5 \pm 40,4$ & 16 & $341,6 \pm 16,3$ & 0,85 N.S. \\
\hline Peso médio das crias $(\mathrm{kg})$ & 211 & $5,7 \pm 14,5$ & 92 & $5,5 \pm 9,6$ & $0,56 \mathrm{~S}$ \\
\hline
\end{tabular}

$\mathrm{p}=0,05$

Tabela 3 - Duração média da lactação (dias), produção média diária (kg), produção total por lactação e respectivos desvios padrão de cabras reagentes e não reagentes ao teste de IDAG para CAE, segundo a idade e os respectivos valores do teste estatístico, no período de 1995-1997. São Paulo, 2003

\begin{tabular}{|c|c|c|c|c|c|c|}
\hline & \multirow[t]{2}{*}{ Idade } & \multicolumn{2}{|c|}{ Reagentes } & \multicolumn{2}{|c|}{ Não Reagentes } & \\
\hline & & $\mathrm{n}$ & Média \pm d.p. & $\mathrm{n}$ & Média \pm d.p. & \\
\hline $\begin{array}{l}\text { Duração média } \\
\text { da lactação } \\
\text { (dias) }\end{array}$ & $\begin{array}{c}12 \mid-24 \\
24-36 \\
36-48 \\
=48\end{array}$ & $\begin{array}{l}54 \\
54 \\
24 \\
66\end{array}$ & $\begin{array}{l}251,5 \pm 110,4 \\
190,7 \pm 90,0 \\
184,0 \pm 68,5 \\
223,3 \pm 72,2\end{array}$ & $\begin{array}{l}39 \\
25 \\
14 \\
16\end{array}$ & $\begin{array}{l}272,0 \pm 119,6 \\
242,5 \pm 107,5 \\
245,0 \pm 84,3 \\
236,5 \pm 62,6\end{array}$ & $\begin{array}{l}0,85 \text { N.S. } \\
2,24 \mathrm{~S} . \\
2,43 \mathrm{~S} . \\
0,67 \text { N.S. }\end{array}$ \\
\hline $\begin{array}{l}\text { Produção } \\
\text { média diária } \\
(\mathrm{kg})\end{array}$ & $\begin{array}{c}12 \longmapsto 24 \\
24-36 \\
36-48 \\
=48\end{array}$ & $\begin{array}{l}54 \\
54 \\
24 \\
66\end{array}$ & $\begin{array}{l}1,2 \pm 0,4 \\
1,7 \pm 0,6 \\
2,3 \pm 0,8 \\
1,6 \pm 0,7\end{array}$ & $\begin{array}{l}39 \\
25 \\
14 \\
16\end{array}$ & $\begin{array}{l}1,5 \pm 0,5 \\
1,9 \pm 0,7 \\
2,1 \pm 0,9 \\
2,1 \pm 0,8\end{array}$ & $\begin{array}{l}2,25 \text { S. } \\
1,34 \text { N.S. } \\
0,59 \text { N.S. } \\
2,02 \text { S. }\end{array}$ \\
\hline $\begin{array}{l}\text { Produção total } \\
\text { por lactação } \\
(\mathrm{kg})\end{array}$ & $\begin{array}{c}12-24 \\
24-36 \\
36-48 \\
=48\end{array}$ & $\begin{array}{l}54 \\
54 \\
24 \\
66\end{array}$ & $\begin{array}{l}333,0 \pm 212,8 \\
311,4 \pm 170,3 \\
403,3 \pm 184,3 \\
365,1 \pm 163,0\end{array}$ & $\begin{array}{l}39 \\
25 \\
14 \\
16\end{array}$ & $\begin{array}{l}411,1 \pm 259,0 \\
427,4 \pm 184,7 \\
497,1 \pm 220,7 \\
485,4 \pm 219,3\end{array}$ & $\begin{array}{l}1,59 \text { N.S. } \\
2,74 \text { S. } \\
1,41 \text { N.S. } \\
2,47 \text { S. }\end{array}$ \\
\hline
\end{tabular}

$\mathrm{p}=0,05$ 
Tabela 4 - Idade ao parto (meses), intervalo interpartos (dias), peso médio das crias ao nascer e desvios-padrão (d.p.) de cabras reagentes e não reagentes a prova de IDAG para CAE, segundo a idade e os valores dos testes estatísticos, no período de 1995-1997. São Paulo, 2003

\begin{tabular}{|c|c|c|c|c|c|c|}
\hline & \multirow[t]{2}{*}{ Idade } & \multicolumn{2}{|c|}{ Reagentes } & \multicolumn{2}{|c|}{ Não Reagentes } & \\
\hline & & $\mathrm{n}$ & Média \pm d.p. & $\mathrm{n}$ & Média \pm d.p. & \\
\hline $\begin{array}{l}\text { Idade ao parto } \\
\text { (meses) }\end{array}$ & $\begin{array}{c}7 \mid-12 \\
12 \mid-24 \\
24 \mid-36 \\
36 \mid-48 \\
=48\end{array}$ & $\begin{array}{r}2 \\
49 \\
54 \\
37 \\
69\end{array}$ & $\begin{array}{l}11,0 \pm 0,0 \\
17,3 \pm 3,6 \\
27,4 \pm 4,5 \\
39,1 \pm 4,8 \\
60,6 \pm 11,2\end{array}$ & $\begin{array}{r}2 \\
31 \\
24 \\
18 \\
17\end{array}$ & $\begin{array}{c}10,5 \pm 0,7 \\
17,4 \pm 4,2 \\
27,3 \pm 4,8 \\
39,1 \pm 4,8 \\
55,9 \pm 10,0\end{array}$ & $\begin{array}{l}1,00 \text { N.S. } \\
0,15 \text { N.S. } \\
0,05 \text { N.S. } \\
0,06 \text { N.S. } \\
1,57 \text { N.S. }\end{array}$ \\
\hline $\begin{array}{l}\text { Intervalo } \\
\text { interpartos } \\
\text { (dias) }\end{array}$ & $\begin{array}{l}12 \mid-24 \\
24 \mid-36 \\
36 \mid-48 \\
=48\end{array}$ & $\begin{array}{r}17 \\
14 \\
6 \\
12\end{array}$ & $\begin{array}{l}330,2 \pm 42,3 \\
318,8 \pm 51,5 \\
346,7 \pm 6,4 \\
357,0 \pm 20,2\end{array}$ & $\begin{array}{r}10 \\
3 \\
1 \\
2\end{array}$ & $\begin{array}{c}347,1 \pm 11,4 \\
334,7 \pm 24,4 \\
343,0 \pm 0,0 \\
323,5 \pm 23,3\end{array}$ & $\begin{array}{l}1,55 \text { N.S. } \\
0,51 \text { N.S. } \\
0,53 \text { N.S. } \\
1,92 \text { N.S. }\end{array}$ \\
\hline $\begin{array}{l}\text { Peso médio das } \\
\text { crias ao nascer } \\
(\mathrm{kg})\end{array}$ & $\begin{array}{c}7 \mid-12 \\
12 \mid-24 \\
24 \mid-36 \\
36 \mid-48 \\
=48\end{array}$ & $\begin{array}{r}2 \\
49 \\
54 \\
37 \\
69\end{array}$ & $\begin{array}{l}3,3 \pm 1,1 \\
4,4 \pm 1,5 \\
5,6 \pm 2,0 \\
6,1 \pm 2,2 \\
6,4 \pm 2,1\end{array}$ & $\begin{array}{r}2 \\
31 \\
24 \\
18 \\
17\end{array}$ & $\begin{array}{l}4,8 \pm 0,4 \\
4,6 \pm 1,4 \\
5,1 \pm 1,9 \\
5,6 \pm 2,1 \\
7,6 \pm 2,5\end{array}$ & $\begin{array}{l}1,90 \text { N.S. } \\
0,77 \text { N.S. } \\
1,00 \text { N.S. } \\
0,76 \text { N.S. } \\
1,97 \text { S. }\end{array}$ \\
\hline
\end{tabular}

$\mathrm{p}=0,05$

uma idade média ao parto 6,6 meses superior do que as não reagentes. $O$ peso médio das crias ao nascer não diferiu entre os grupos. Entretanto, as crias de mães positivas com idade maior ou igual a 48 meses, apresentaram peso ao nascer $1,2 \mathrm{~kg}$ inferior ao encontrado para as crias nascidas de mães com sorologia negativa (Tabelas 2 e 4). A idade ao primeiro parto e o intervalo interpartos (Tabelas 2 e 4) não foram diferentes entre os grupos.

\section{Discussão e Conclusões}

A freqüência de ocorrência da Artrite Encefalite Caprina, no rebanho estudado foi bastante elevada sendo superior aos valores encontrados por outros autores em vários estados brasileiros $90,10,11,12,13,14$. O aumento do número de casos, notado na segunda avaliação sorológica do rebanho, pode ser atribuído ao aumento do número de animais do plantel, o que favorece a transmissão horizontal da doença ${ }^{16,18,19,20}$. Todavia, a diminuição de animais em 1997 não contribuiu para a diminuição da prevalência da doença, o que pode estar relacionado a soroconversão de animais negativos e a manutenção de animais positivos assintomáticos no plantel.
O aumento do número de doentes com o avançar da idade também foi evidenciado por outros autores ${ }^{11,16}$ e pode estar intimamente relacionado com a transmissão horizontal da doença ${ }^{4,16,17,18,20} \mathrm{e}$ a demora na soroconversão após o vírus ter sido transmitido às crias ${ }^{17,19}$.

Os efeitos da CAE sobre a produção leiteira foram semelhantes aos encontrados por outros autores ${ }^{21,23,24}$. Em relação à duração média da lactação, a estratificação dos animais permitiu verificar que as maiores diferenças ocorreram entre as cabras multíparas, o que também foi observado por Greenwood $^{21}$.

A média diária de produção leiteira das cabras reagentes ao vírus da CAE foi inferior aos valores encontrados para as não reagentes, representando perdas ao redor de $20 \%$ nas faixas etárias entre 12 e 24 meses e maior ou igual a 48 meses. Perdas ao redor de $12 \%$ foram encontradas para animais de primeira lactação ${ }^{23}$, enquanto que para cabras multíparas foram encontrados valores ${ }^{21}$ bastante semelhantes aos relatados nesse trabalho.

O vírus da CAE tem sido associado a prejuízos econômicos, estando relacionado com a diminuição dos teores de gordura e proteína do leite ${ }^{23}$, aumento do número de 
células somáticas ${ }^{4,25}$, e ocorrência de mastite intersticial ${ }^{4,16}$ mesmo nos animais que ainda não desenvolveram a glândula mamária ${ }^{4}$. Esses efeitos deletérios do vírus sobre a glândula mamária podem ser a causa direta da menor produção leiteira. Entretanto, outros fatores, como a menor ingestão de alimentos, por dificuldade de locomoção, em decorrência de artrite crônica ${ }^{15}$ e a maior incidência de doenças entre os animais infectados pelo vírus da $\mathrm{CAE}^{24}$ poderiam indiretamente, ocasionar a queda na produção leiteira destes animais.

Não foram observadas implicações da CAE na esfera reprodutiva no que se refere à idade ao primeiro parto e aos intervalos interpartos. A maior idade ao parto e o menor peso das crias ao nascer de mães soropositivas sugerem a existência de falhas reprodutivas que também foram observadas por outros autores ${ }^{21,24}$. A ocorrência de hiperplasia folicular linfóide no útero da uma cabra infectada indica que o útero pode ser um órgão-alvo e foco de replicação viral e que, tanto o útero como o trato genitourinário podem servir como potencial fonte de infecção perinatal ${ }^{6,16}$. Associando estas condições, às características de vírus lento ${ }^{1}$, pode-se esperar que as modificações causadas pelo vírus no útero sejam mais evidentes nos animais mais velhos.

Embora o desenho do presente estudo não tenha permitido a aferição do momento exato da contaminação dos animais pelo vírus da CAE, em função do diagnóstico sorológico ter sido realizado anualmente, pôde-se verificar o impacto econômico causado pela doença em uma propriedade, cuja prevalência foi muito elevada.

Assim, através da avaliação dos aspectos produtivos e reprodutivos, foi possível identificar que a CAE teve influência significativa na queda da produção leiteira, podendo causar uma menor performance reprodutiva no que se refere à idade ao parto $\mathrm{e}$ ao peso das crias ao nascer. Os índices reprodutivos idade ao primeiro parto e intervalo interpartos não apresentaram diferenças significantes entre os grupos estudados.

Os resultados encontrados neste e em outros trabalhos que verificaram os efeitos do vírus da CAE na produtividade sugerem que devam ser dirigidos esforços por parte das associações de criadores, entidades de ensino, pesquisa e órgãos governamentais no sentido de controlar a doença em nosso meio.

\section{Caprine arthritis encephalitis: productive and reproductive aspects evaluation in infected and no infected goats}

\section{Abstract}

The present study was carried out to compare the productive and reproductive aspects of Caprine Arthritis Encephalitis virus (CAEv) antibody-positive and antibody-negative dairy goats. The agar gel immunodiffusion test (AGID) was performed, using the following antigens from the CAEv: gp135, a glicoprotein and p28, an internal structural protein. A goat herd coming from the contry of São Paulo state was evaluated for 24 months. Three serum tests were performed with intervals of 12 months. The frequency of occurrence of CAE, obtained for the three different moments of observation was $60,1 \%$, $74,1 \%, 70,5 \%$, respectively, and the total rate was $68.3 \%(566 / 829)$. The percentage of reagents to the CAEv rose significantly as the age grew. The average lactation length (in days) was lower for positive goats, significant values were found for goats of 24 to 36 months and for 36 to 48 months ones. The CAEv antibody-positive goats presented a mean daily milk yield (kg./day) lower than CAEv antibody-positive goats, with significant values for the groups: 12 to

\section{Key-words:}

Caprine arthritis encephalitis. Milk production.

Reproduction. Lentivirus.

Goats. 
24 months and 48 months or more. The total production for lactation was $21.5 \%$ lower for positive goats. The CAE did not influenced the reproductive aspects in this study on first kidding and on kidding interval. However, the average of kidding age was bigger between the reagents, when compared with not reagents, being statistically significant. Also the weight of kids, born from positive goats with age of 48 months or higher, was lower than that of the ones born from negative mothers.

\section{Referências}

1 NARAYAN, O. et al. Slow virus replication: the role of macrophages in the persistence and expression of visna virus of sheep and goats. Journal of General Virology, v. 59 , n. 2 , p. $345-356,1982$.

2 CORK, L. C. et al. Infectious leukoencephalomyelitis of young goats. Journal of Infectious Diseases, v. 129, n. 2, p. 134-141, 1974.

3 CRAWFORD, T. B.; ADAMS, D. S.; CHEEVERS, W. P. Chronic arthritis in goats caused by a retrovirus. Science, v. 207, n. 29, p. 997-999, 1980.

4 LERONDELLE, C.; FLEURY, C.; VIALARD, J. Le glande mammaire: organe cible de l'infection par le virus de l'arthrite et de l'encéphalite caprine. Annales de Recherches Veterinaires, v. 20, n. 1, p. 57-63, 1989.

5 SERAKIDES, R.; NUNES, V. A.; PEREIRA, M. F. Estudo clínico, anatomopatológico e imuno-histoquímico de pulmões de cabras naturalmente infectadas pelo vírus da artrite encefalite caprina (CAE). Arquivo Brasileiro de Medicina Veterinária e Zootecnia, v. 48, n. 4, p. 415424, 1996.

6 ALI, O. A. Caprine arthritis-encephalitis related changes in the uterus of a goat. Veterinary Record, v. 121, n. 6, p. 131-132, 1987.

7 ADAMS, D. S. et al. Global survey of serological evidence of caprine arthritis-encephalitis virus infection. Veterinary Record, v. 115, n. 19, p. 493-495, 1984.

8 MOOJEN. V. et al. Evidência de infecção pelo lentivirus (maedi-visna/ artrite-encefalite caprina) em caprinos no Rio Grande do Sul, Brasil (Comunicação Científica). Arquivos da Faculdade de Veterinária UFRGS, v. 14, p. 77-78, 1986.

9 CUNHA, R. G.; NASCIMENTO, M. D. Ocorrência de anticorpos para o vírus da artrite encefalite caprina em soros de caprinos do Estado do Rio de Janeiro. Revista Brasileira de Medicina Veterinária, v. 17, n. 2, p. 72-75, 1995.

10 D'ANGELINO, J. L. et al. Ocorrência da artrite encefalite caprina no Estado de São Paulo - Brasil. Arquivos da Escola de Medicina Veterinária da Universidade Federal da Bahia, v. 16, n. 1, p. 60-66, 1993.

11 FERNANDES, M. A. Artrite encefalite caprina.
Contribuição para o estudo epidemiológico em rebanhos leiteiros criados no Estado de São Paulo. 1997. 83 f. Dissertação (Mestrado) - Faculdade de Medicina Veterinária e Zootecnia, Universidade de São Paulo, São Paulo, 1997.

12 GARCIA, M. et al. Caprine arthritis-encephalitis (CAE). Ocurrence of positive sera in goats raised in Brazil. Tropical Animal Health and Production, v. 24, n. 3, p. 164, 1992

13 PINHEIRO, R. R. et al. Presença da artrite encefalite caprina a vírus (CAEV) em Teresina-Piauí. In: CONGRESSO BRASILEIRO DE MEDICINA VETERINÁRIA, 24., 1996, Goiânia. Anais... Goiânia: Sociedade Goiânia de Veterinária, 1996. p. 161.

14 SARAIVA NETO, A. O. et al. Estudo soroepidemiológico da artrite encefalite caprina em Pernambuco. Pesquisa Veterinária Brasileira, v. 15, n. 4, p. 121-124, 1995

15 CRAWFORD, T. B.; ADAMS, D. S. Caprine arthritisencephalitis: clinical features and presence of antibody in selected goat populations. Journal of American Veterinary Medical Association, v. 178, n. 7, p. 713$719,1981$.

16 LARA, M. C. C. S. H. Artrite-encefalite dos caprinos :aspectos clínicos e epidemiológicos, 2002. 247 f. Tese (Doutorado) - Faculdade de Medicina Veterinária e Zootecnia, Universidade de São Paulo, São Paulo, 2002.

17 ROWE, J. D. et al. Risk factors associated with the incidence of seroconversion to caprine arthritisencephalitis virus in goats on California dairies. American Journal of Veterinary Research, v. 53, n. 12, p. 23962403, 1992.

18 GUEDES, M. I. M. C., SOUZA, J. C. A.; GOUVEIA, A. M. G. Caprine arthritis encephalitis virus experimental infection in newborn kids. Arquivo Brasileiro de Medicina Veterinária e Zootecnia, v. 53, n. 1, p. 15-20, 2001.

19 LARA, M. C. C. S. H. et al. Infecção experimental do vírus da artrite encefalite dos caprinos em cabritos. Arquivos do Instituto Biológico, v. 70, n. 1, p. 51-54, 2003.

20 SMITH, M. C.; SHERMAN, D. M. Musculoskeletal 
system. In: SMITH, M. C.; SHERMAN, D. M. Goat medicine. Philadelphia: Lea \& Febiger, 1994. p. 63-121.

21 GREENWOOD, P. L. Effects of caprine arthritisencephalitis virus on productivity and health of dairy goats in New South Wales, Australia. Preventive Veterinary Medicine, v. 22, n. 1-2, p. 71-87, 1995.

22 RUSSO, P. et al. Caprine arthritis-encephalitis virus: detection of proviral DNA in lactoserum cells. Veterinary Record, v. 140, n. 18, p. 483-484, 1997.

23 SMITH, M. C.; CUTLIP, R. Effects of infection with caprine arthritis-encephalitis virus on milk production in goats. Journal of American Veterinary Medical Association, v. 193, n. 1, p. 63-67, 1988.

24 VON MOCKENHAUPT, C.; BAUER, K. Untersuchungen zur caprinen arthritis-enzephalitis in Bayern und der einsefluss seuchen-hygienischer massnahmen auf den verlauf dieser krankheit. Tierärztliche Umschau, v. 42, n. 12, p. 966-970, 1987.

25 RYAN, D. P.; GREENWOOD, P. L.; NICHOLLS, P. J. Effect of caprine arthritis-encephalitis virus infection on milk cell count and $\mathrm{N}$-acetyl-b-glucosaminidase activity in dairy goats. Journal of Dairy Research, v. 60, n. 3, p. 299-306, 1993.

26 BOHLAND, E. Artrite Encefalite Caprina: avaliação dos aspectos produtivos e reprodutivos de animais infectados e não infectados, 1998. 96 f. Dissertação (Mestrado) - Faculdade de Medicina Veterinária e Zootecnia, Universidade de São Paulo, São Paulo, 1998.

27 BIRGEL, E. H. Leucose linfática e enzoótica dos bovinos adultos, aspectos clínicos e diagnóstico. In: BIRGEL, E. H.; BENESI, F. J. Patologia clínica veterinária. São Paulo: Sociedade Paulista de Medicina Veterinária, 1982. p. 242-260.

28 CUTLIP, R. C.; JACKSON, T. A.; LAIRD, G. A. Immunodifusion test for Ovine Progressive Pneumonia. American Journal of Veterinary Research, v. 38, n. 7, p. 1081-1084, 1977.

29 DEAN, A. G. et al. Epi Info, Version 6: a word processing, database, and statistics program for epidemiology on microcomputers. Atlanta, Georgia, USA: Centers for disease control and prevention, 1994.

30 BERQUÓ, E. S.; SOUZA, J. M. P.; GOTLIEB, S. L. D. Bioestatística. 2. ed. São Paulo: EPU, 1981. 350 p. 